\title{
ARTIGO
}

d. 10.22481/praxisedu.v15i33.5290

\section{“EDUCANDO COM O LIVRO E A ENXADA": ROBERT KING HALL E O PROGRAMA DE EDUCAÇÃO RURAL DO INEP (1949-1951)}

\author{
“CON EL LIBRO Y LA AZADA ": ROBERT KING HALL Y EL PROGRAMA DE \\ EDUCACIÓN RURAL DEL INEP (1949-1951)
}
“WITH THE BOOK AND THE HOE ": ROBERT KING HALL AND THE RURAL EDUCATION PROGRAM OF THE INEP (1949-1951)

Adriana Mendonça Cunha

Universidade Federal de Sergipe - Brasil

Dilton Cândido Santos Maynard

Universidade Federal de Sergipe - Brasil

\begin{abstract}
Resumo: Este artigo analisa a colaboração do pesquisador estadunidense Robert King Hall junto ao programa de educação rural, coordenado pelo Instituto Nacional de Estudos Pedagógicos (INEP) na década de 1940, no Brasil. Lançado pelo governo federal em 1946, o projeto tinha como metas combater os altos índices de analfabetismo, promover uma maior qualificação da mão de obra no campo e conter o êxodo rural. Coube ao INEP organizar, coordenar e fiscalizar a construção de escolas rurais, além de promover a capacitação dos docentes que atuariam nestas instituições. Em 1949, Hall foi convidado pelo instituto para trabalhar como técnico, ministrando um curso para professores primários no Rio de Janeiro e fazendo uma análise do projeto. Nosso trabalho estuda a influência de Hall junto ao programa. Para tanto, examinamos os relatórios produzidos pelo pesquisador e publicados na Revista Brasileira de Estudos Pedagógicos, matérias de jornais e também leis e decretos referentes ao ensino rural. Enquanto pesquisador estrangeiro e colaborador do INEP, Hall realizou uma análise crítica, indicando mudanças importantes a serem realizadas no projeto. Ao mesmo tempo em que propunha reformas baseadas em experiências e referencias estadunidenses.
\end{abstract}

Palavras-chave: Educação rural. Relações Brasil-EUA. Robert King Hall.

Abstract: The purpose of this article is to analyze the contribution of the American researcher Robert King Hall to the rural education program, coordinated by the National Institute of Pedagogical Studies (INEP), at the 1940 decade, in Brazil. The project aimed to fight high rates of illiteracy, promote a greater qualification of labor on the field and contain rural exodus. It was incumbent upon INEP to organization, coordination, and inspection of rural school construction, besides promoting the training of the Teachers who would act in those institutions. In 1949, Hall was hired by the institute to work as a technician, teaching an improvement course for primary Teachers in Rio de Janeiro and to produce an analysis of the program. The paper examines the reports produced by the American researcher 
about the program, published in the Brazilian Magazine of Pedagogical Studies, newspaper articles, laws and decrees referring to rural education. As a foreign researcher and collaborator of the INEP, Hall did a critical analysis, pointing changes to be executed in the Project. At the same time, he proposed a rural teaching model based on American experience and references.

Key Words: Rural education. Brazil-EUA Relations. Robert King Hall.

Resumen: El propósito de este artículo es analizar la colaboración del investigador estadounidense Robert King Hall con el programa de educación rural, coordinado por el Instituto Nacional de Estudios Pedagógicos (INEP) en la década de 1940, en Brasil. El proyecto fue lanzado por el gobierno federal en 1946 y tenía como objetivos combatir los altos índices de analfabetismo, promoviendo una mayor calificación de la mano de obra en el campo y contener el éxodo rural. Incumbió a INEP organizar, coordinar y inspeccionar la construcción de escuelas rurales, además de promocionar la capacitación de los docentes que actuarían en estas instituciones. En 1949, Hall fue invitado por el instituto para trabajar como técnico, suministrando un curso para profesores primarios en Río de Janeiro y haciendo un análisis del proyecto. Nuestro objetivo fue detectar los posicionamientos de Hall en relación a la enseñanza rural brasileña, evaluando el grado de influencia que él pudo haber ejercido junto al programa. Para ello, examinamos los informes producidos por el investigador y publicados en la Revista Brasileña de Estudios Pedagógicos, materias de periódicos y también leyes y decretos referentes a la enseñanza rural. Como investigador extranjero y colaborador del INEP, Hall realizó un análisis crítico, indicando cambios importantes a ser realizados en el proyecto. A la vez que proponía reformas basadas en experiencias y referencias estadunidenses.

Palabras Clave: Educación rural. Relaciones Brasil-EE.UU. Robert King Hall.

\section{Introdução}

Este artigo analisa a colaboração do pesquisador estadunidense Robert King Hall junto ao programa de educação rural coordenado pelo Instituto Nacional de Estudos Pedagógicos (INEP) entre a década de 1940 e o começo dos anos 1950 no Brasil. Lançado pelo governo federal em 1946, o projeto tinha como metas combater os altos índices de analfabetismo, conter o êxodo rural e qualificar mão de obra para o campo. Coube ao INEP organizar, coordenar e fiscalizar a construção de escolas rurais pelo interior do país, além de promover cursos para capacitação dos docentes que atuariam nestas instituições. Robert King Hall foi contratado pelo instituto para trabalhar como técnico, ministrando um seminário de aperfeiçoamento para professores primários e produzindo uma análise do projeto.

Professor do Teachers College da Universidade de Columbia, Hall (1912-1981) era Bacharel of Arts pela Lake Forest University (1933), Masters of Arts pelas universidades de Harvard (1935) e Chicago (1936) e doutor em Educação Comparada pela Universidade de Michigan (1941). Antes de ocupar o cargo de docente em Columbia, o pesquisador atuou na Cranbrook School, uma importante instituição de ensino privado em Michigan. Prestou 
assessoria técnica para países como Brasil, Irã e Arábia Saudita. Além disso, trabalhou a serviço do governo estadunidense no Japão após a Segunda Guerra Mundial (1939-1945), ocupando o cargo de Chefe da Seção de Educação do Estado Maior e Chefe da Reorganização do Ensino Japonês durante a ocupação do país pelos Aliados (1945-1952).

Durante a década de 1940, em meio aos trabalhos desenvolvidos em instituições e a serviço do seu país, Hall realizou uma série de viagens ao Brasil para estudar detidamente nosso sistema educacional. Para realizar tais investigações contou com o auxílio de bolsas de estudo fornecidas por instituições como o Itamaraty e a Universidade de Michigan, chegando a contar com um avião disponibilizado para seu transporte, fornecido pela Pan American Airways, empresa aérea estadunidense.

Estas viagens de Hall e seus interesses de pesquisa estavam diretamente ligados ao contexto de aproximação entre Brasil e Estados Unidos durante a década de 1940. Cabe lembrar que, desde os anos 1930, com a adoção da Política da Boa Vizinhança, os estadunidenses buscaram estreitar os laços políticos, econômicos e culturais com os vizinhos latino-americanos. A promoção destes contatos resultava de diversos fatores, a saber:

[...] A depressão econômica dos anos 30, a ascensão de Hitler na Alemanha, suas ambições expansionistas, ao lado daquelas de Mussolini na Itália, sinalizavam a possibilidade de um conflito internacional de grandes proporções. Os analistas norte-americanos compreenderam que a América Latina era fundamental para o jogo de poder no continente, e portanto, precisava ser mantida como sua aliada (PRADO, 1995, p. 55).

Preocupavam aos EUA o avanço nazista na Europa e as relações étnicas, comerciais e militares que os alemães tinham com a América Latina, especialmente Argentina e Brasil, países influentes regionalmente e com um número considerável de imigrantes desta nação (MACCANN, 1995; MOURA, 1991; LOCHERY, 2015). Pensando em afastar esta ameaça, em 1938, o governo estadunidense criou a Divisão de Relações Culturais do Departamento de Estado, dando forma a uma cooperação intelectual.

Dois anos depois, foi criado o Office of the Coordinator of Inter-American Affairs (OCIAA) que tinha a função de estimular a economia latino-americana e produzir programas de educação, cultura e propaganda (MOURA, 1991). Filmes, documentários, revistas, programas de rádio, entre outros meios foram utilizados para criar um sentimento de solidariedade hemisférica. Os intercâmbios de estudantes foram ampliados e estimulados com a concessão de bolsas de estudo. Robert King Hall foi um dos pesquisadores diretamente beneficiados por esta política. 
A chegada da Segunda Guerra Mundial e a demora de Getúlio Vargas em explicitar preferência por um lado fez com que os EUA voltassem sua atenção para o Brasil. A posição estratégica do Nordeste, a ameaça dos imigrantes e os recursos naturais brasileiros deram grande poder de barganha ao governo Vargas, que soube aproveitar o conflito para obter ganhos políticos e econômicos que permitiram modernizar o país (LOCHERY, 2015).

A partir de 1940, Robert King Hall voltou sua atenção para o Brasil. Além dos auxílios financeiros, ele contou ainda com o apoio do INEP, na figura de seu diretor, o prof. Lourenço Filho, que deu acesso a fontes e estabeleceu contato direto com o pesquisador estadunidense. Suas passagens pelo país foram amplamente divulgadas em diversos periódicos, a exemplo do Diário de Notícia (RJ), Correio Paulistano (SP), O Jornal (RJ), dentre outros. Hall parecia possuir grande prestígio tanto na imprensa, onde não só concedia entrevistas como publicava textos, quanto entre intelectuais ligados ao campo educacional, como foi o caso de Lourenço Filho (1897-1970), Arthur Ramos (1903-1949), Gilberto Freyre (1900-1987) e até mesmo o ministro da educação, Gustavo Capanema (1900-1985).

Não por acaso, em 1949, Hall foi contratado pelo INEP para prestar assessoria técnica em um programa de educação rural do governo federal. Suas ações consistiram em ministrar um curso para professores primários e fazer uma viagem a Sergipe, onde conheceu de perto o programa e realizou uma avaliação dele. Deste trabalho originaram-se dois relatórios publicados na Revista Brasileira de Estudos Pedagógicos (RBEP): Observações e Impressões sobre o Ensino Rural no Brasil (1950) e Problemas de Educação Rural (1950). É justamente a partir destes textos que analisamos quais as impressões, sugestões e críticas realizadas por Hall e se elas tiveram algum impacto efetivo no programa.

\section{Combater o analfabetismo e educar o homem para o campo}

As discussões em torno de um ensino tipicamente rural não eram novidade no Brasil dos anos 1950. Desde o final do século XIX, políticos e intelectuais propunham a criação de instituições destinadas a preparar o homem para a vida no campo. Voltados para os filhos de lavradores, crianças órfãs e de rua, os patronatos e aprendizados agrícolas procuraram, na Primeira República (1889-1930), formar domésticas e trabalhadores para a pecuária e a agricultura (NASCIMENTO, 2004; MENDONÇA, S., 2016). Já nos anos 1930, o movimento conhecido como Ruralismo Pedagógico entrou em cena, reivindicando a valorização do meio rural e a criação de escolas voltadas a este fim. 
Foi, contudo, na década seguinte que o crescimento industrial e urbano provocou efetiva preocupação por parte do Estado para com a população rural, por conta da migração em direção às cidades. Buscando solucionar o problema do êxodo e dos altos índices de analfabetismo - mais de metade da população brasileira não era alfabetizada - o governo federal criou um programa nacional de educação rural. Através dele, os estados e a União assinavam um contrato para construção de escolas primárias e normais em regiões rurais. $\mathrm{O}$ então presidente Eurico Gaspar Dutra, em mensagem ao Congresso Nacional em 1947, exaltou o programa e ressaltou a sua importância visto que ele promoveria não apenas a erradicação do analfabetismo mas, "com a enxada e o livro", formaria excelentes profissionais no cultivo da terra (DUTRA, 1947, p.30).

O projeto ficou a cargo do Instituto Nacional de Estudos Pedagógicos. Cabia ao INEP criar um modelo de escola, assinar os contratos com os governos estaduais e fiscalizar as construções. Estas instituições deveriam possuir currículos voltados para atividades ligadas ao campo, como puericultura, agricultura, pecuária e jardinagem. Disciplinas como francês deveriam ter pouco ou nenhum espaço, diferenciando-se dos planos de estudos das escolas urbanas.

Ao se organizar um modelo de ensino voltado para a valorização do meio rural, fixação do homem no campo e a promoção da qualificação de mão-de-obra, o programa preconizava a formação de um novo tipo de professor, adaptado às exigências do meio ao qual estaria inserido. Por isso, as escolas normais eram peças-chaves no sucesso deste empreendimento. Construídas com recursos federais, estas instituições deveriam selecionar jovens da própria localidade para ingressarem no curso e se qualificarem para atuar nas escolas primárias da região. Os currículos deveriam ser voltados para a aprendizagem de técnicas de agricultura, puericultura, jardinagem e criação de pequenos animais.

Levando em consideração o fato de que as escolas normais estavam sendo construídas em paralelo às escolas primárias, e o ensino normal tradicional não seria capaz de formar o tipo de professor almejado, o INEP iniciou um programa de treinamento através do qual professores, diretores e coordenadores recebiam capacitação para atuar nas escolas rurais por meio de cursos realizados na sede da instituição, no Rio de Janeiro.

Organizados anualmente, os cursos recebiam professores de todo o país "com o objetivo de formar uma elite capaz de assumir a responsabilidade da direção da educação nos diversos setores educacionais" (BRAGA, 1950, p. 13). Os participantes, selecionados pelos departamentos estaduais de educação, recebiam uma bolsa de estudos para financiar a viagem. 
Ao voltarem aos seus estados, os professores se comprometiam a integrar o corpo docente das escolas primárias rurais e os diretores e coordenadores ficavam responsáveis por organizar, em nível estadual, cursos semelhantes. Esta prática foi bastante comum durante toda a década de 1940 em vários estados que possuíam escolas primárias rurais. No Paraná, por exemplo, além dos cursos eram distribuídas entre os professores cartilhas com diversas orientações (SHELBAUER, 2014).

Para organizar e ministrar o curso de aperfeiçoamento para professores primários rurais, no ano de 1949, o INEP contratou o professor Robert King Hall. O diretor do instituto, Murilo Braga, justificava que a contratação se dava "não só pela experiência que possui no trato dessas questões, como pelo profundo conhecimento dos problemas do Brasil" (BRAGA, 1950, p.13).

\title{
Robert King Hall e o programa de educação rural do INEP
}

Em dezembro de 1949, Robert King Hall ministrou, no Rio de Janeiro, um seminário de três semanas para 160 professores de várias regiões do país. Intitulado Problemas de Educação Rural, o curso foi amplamente divulgado pela imprensa. Como exemplo, apresentamos uma matéria divulgada nos periódicos O Jornal (RJ), Diário de Notícias (RJ) e Gazeta de Notícias (RJ). Publicado em 15 de dezembro de 1949, com o mesmo conteúdo, o texto anunciava:

\begin{abstract}
Desenvolvendo os seus cursos de formação e aperfeiçoamento de professores primários, o Instituto Nacional de Estudos Pedagógicos do Ministério da Educação e Saúde, organizou e está realizando um curso intensivo sobre formação de professores rurais, em forma de seminário, visando oferecer aos mestres de todo o Brasil que frequentam as aulas de aperfeiçoamento do INEP, um conhecimento mais apurado das modernas técnicas de ensino conforme a ambientação rural. A frente dos trabalhos acha-se o professor Robert King Hall, do Teachers College da Universidade de Columbia, especialmente convidado para dirigir as reuniões ${ }^{1}$.
\end{abstract}

No ano seguinte, o INEP publicou o curso em forma de texto na Revista Brasileira de Estudos Pedagógicos. Contendo 106 páginas, nele Hall detalhava as datas e horários dos encontros, o plano de trabalho, a metodologia, os temas debatidos e a bibliografia utilizada na sua elaboração. Buscaremos aqui apresentar, resumidamente, os principais temas abordados pelo pesquisador no seminário.

\footnotetext{
${ }^{1}$ Curso de problemas de educação rural. O Jornal. Rio de Janeiro, 15 dez. de 1949, ano XXXI, nº 9092, p.03.
} 
Durante o curso discutiram-se seis temas que giraram em torno de dois pontos principais: a escola primária rural e o professor destinado a esta instituição. Com relação à escola, três problemas foram levantados por Hall: sua integração na comunidade, seu papel na segurança nacional e a construção do currículo escolar. Já no tocante ao professor, abordou-se a questão da formação para o ensino na zona rural e a função dos docentes no processo de desenvolvimento econômico do país.

Discorrendo sobre a integração da escola primária na comunidade rural, o pesquisador estadunidense procurou dar ênfase aos "elementos básicos de uma boa escola primária”, cuja função era promover "a realização dos ideais democráticos na vida prática do aluno" (HALL, 1950, p.22). Já neste primeiro tema foi possível identificar uma ideia apresentada frequentemente ao longo do curso: embora estivesse voltado para a comunidade local, o ensino primário rural deveria sempre levar em consideração o papel que todo cidadão e comunidade, fosse ela rural ou urbana, deveria desempenhar em favor do desenvolvimento do seu país e da solidariedade internacional. Mas de que solidariedade falava Robert King Hall?

A resposta a esta pergunta pode ser encontrada no último tema, também referente à escola, intitulado "O papel da escola primária rural na segurança nacional”. Na mais política das temáticas, Robert King Hall, deixa clara sua posição em defesa da democracia e da civilização Ocidental, faz referência à Guerra Fria e lança várias críticas ao regime comunista. Para o pesquisador, a Segurança Nacional estendia-se não apenas ao plano político, mas também educacional. Segundo ele: "Existe uma crise (o mundo já está numa luta de vida ou morte entre duas ideologias extremamente poderosas e aparentemente irreconciliáveis): comunismo versus democracia ocidental" (HALL, 1950, p.91).

A afirmação de Hall, ao colocar em relevo a Segurança Nacional como vetor para o debate sobre educação, nos remete diretamente ao clima de paranoia comunista que tomava conta do mundo naquele período inicial da Guerra Fria. Nos Estados Unidos, diversos intelectuais, artistas e funcionários públicos foram perseguidos, acusados de estarem a serviço dos soviéticos (HOBSBAWM, 1997; VALIM, 2006). Segundo Hobsbawm (1997), a certeza de que havia,

Um inimigo externo ameaçando os Estados Unidos não deixava de ser conveniente para governos americanos que haviam concluído, corretamente, que seu país era agora uma potência mundial e que ainda viam o ‘isolacionismo' ou protecionismo defensivo como seu grande obstáculo interno (p. 232). 
Corroborando com esta crença, Robert King Hall chamava a atenção para a importância da solidariedade internacional e da inviabilidade em manter uma posição de neutralidade no conflito. Para ele, "o exemplo da organização doméstica de um país favorece um lado ou outo, na estratégia psicológica” (HALL, 1950, p. 91). E como uma guerra seria desastrosa, diante das "novas armas e técnicas que transformarão qualquer luta mais séria numa guerra de sobrevivência” (p.91), a única maneira viável de combater o comunismo seria através de meios pacíficos.

Ao abordar a construção do currículo escolar, Hall defendia a adoção de um modelo no qual houvesse uma reconstrução constante, determinada pelas "necessidades históricas e sociais do meio no qual estavam inseridas", com conhecimentos práticos e tendo em vista a formação de cidadãos críticos. Neste modelo, deveriam ser os professores e não o Estado, os responsáveis pela elaboração do programa. Em função disso, a formação dos docentes tornava-se parte crucial no processo de organização do ensino rural.

Para que ela fosse satisfatória, alguns requisitos básicos deveriam ser priorizados: a seleção dos docentes, o treinamento e os incentivos à carreira. Um bom professor primário rural deveria, segundo Hall, possuir três características fundamentais: pertencer a comunidade onde atuaria, ou seja, provir da zona rural, ser dotado de amor ao seu trabalho e possuir qualidades intelectuais e morais.

Sua formação e treinamento deveriam seguir um plano completo de estudos que pudesse oferecer conhecimento, habilidade e didática suficientes para transmitir aos alunos os ensinamentos indispensáveis ao seu desenvolvimento no meio rural. Ademais, era necessária a criação de mecanismos de incentivo à profissão por meio da valorização do professor através do "reconhecimento público e de uma posição de relevo na comunidade" (HALL, 1950, p.38). Oferecer boas condições de vida e de trabalho, segurança e "remuneração razoável", "proporcionais ao preparo, às dificuldades, e à estabilidade do cargo" (p. 39).

Para Hall, existia uma estreita ligação entre a formação, o trabalho do professor rural e o crescimento econômico da comunidade e, consequentemente, do país. Uma formação completa, que fornecesse conhecimento e preparo técnico aos docentes, permitiria a eles preparar seus alunos para uma vida produtiva, inserindo-os nos conhecimentos necessários ao desenvolvimento econômico e social da sua comunidade. Contribuindo para a valorização do campo, controle do êxodo e a manutenção do equilíbrio entre as atividades urbanas e rurais.

Após o término do curso Problemas de Educação Rural, no Rio de Janeiro, Robert King Hall realizou uma viagem a Sergipe, acompanhado de Murilo Braga e de técnicos do INEP. Em Aracaju, os visitantes foram recebidos pelo diretor do Departamento de Educação, 
o professor Acrísio Cruz. O objetivo era conhecer de perto a execução do programa do governo federal, organizado pelo INEP e com o qual Hall colaborava como consultor técnico.

A escolha de Sergipe justificava-se pelo seu tamanho territorial, por ser um estado eminentemente rural e ter um grande número de escolas primárias rurais, financiadas pela União, em funcionamento. Isso permitiu transformá-lo em projeto piloto do programa, servindo de base para a avaliação do pesquisador estadunidense. Durante sua passagem,

O prof. King Hall percorreu o oeste e o norte de Sergipe, numa extensa região entre Aracaju e Paulo Afonso. Aracaju e Propriá, no Baixo São Francisco. Visitou vinte e quatro escolas rurais, três grupos escolares e uma escola normal rural. ${ }^{2}$

Concluída a viagem, Robert King Hall produziu um relatório, posteriormente publicado na Revista Brasileira de Estudos Pedagógicos (RBEP) em duas edições: no boletim $\mathrm{n}^{\circ} 38$, de janeiro de 1950 , e no de $\mathrm{n}^{\circ}$ 64, de junho do mesmo ano. Intitulado Observações $e$ Impressões sobre o ensino rural no Brasil o relatório foi produzido e entregue a Murilo Braga por Robert King Hall, em janeiro de 1950. Contendo 11 páginas, nele, Hall apresentava algumas considerações sobre o programa a partir de observações realizadas durante as cinco semanas em que trabalhou como técnico para o instituto.

Ao iniciar o texto, Hall revelava ter tido dúvidas quanto a viabilidade do projeto. Estas, "fundavam-se em quatro grandes temores", a saber: 1- utilização dos recursos para fins políticos; 2- falta de continuidade do programa, devido a mudanças no governo; 3investimento na construção de prédios escolares, sem efetiva melhoria da educação; 4abandono, por parte do INEP, das atividades de pesquisa e treinamento. Os dois primeiros pontos referiam-se a questões político-partidárias e nos chamam a atenção para o conhecimento que Hall possuía da sociedade brasileira.

O pesquisador estadunidense compreendia que, no Brasil, a barganha política e os interesses de uma minoria, detentora do poder, eram fortes o suficiente para influenciar e, na maioria das vezes, determinar os rumos das reformas empreendidas no campo educacional. Sendo bastante comum uma descontinuidade dos projetos, abandonados com a troca de governo. O controle dos recursos financeiros poderia influenciar a sua distribuição, deixandoa condicionada ao apoio recebido pelos políticos locais.

\footnotetext{
${ }^{2}$ Bem impressionado com o ensino rural no Brasil. Diário de Notícias. Rio de Janeiro, 15 jan. de 1950, ano XX, $\mathrm{n}^{\mathrm{o}} 8.355$, p. 22.
} 
Hall alertava para o fato de que construir prédios escolares pelo país não garantiria uma melhoria efetiva da educação brasileira. Só trariam resultados se fossem acompanhados de investimento em atividades de pesquisa e capacitação. Cabendo ao INEP responsabilizarse por estas ações. Por isso, era bastante perigoso atribuir a este órgão a execução de um projeto de tamanha amplitude, visto que ele poderia ocupar maior espaço, deixando relegadas, a segundo plano, as demais competências da instituição.

Após reafirmar que "todos êsses temores ainda prevalecem e, em minha opinião, os perigos não foram nem podem ser completamente removidos", Hall elencou as principais vantagens apresentadas pelo programa, que o fizeram reavaliar sua posição. A primeira delas fazia referência ao processo de seleção e formação do professor destinado à escola primária rural. O programa recomendava a escolha de docentes provenientes das zonas rurais, criava escolas normais rurais para formá-los e previa a construção de uma residência, anexa à escola, que serviria de moradia para o professor. Essas medidas eram de fundamental importância para o sucesso do programa, pois evitavam problemas ocasionados pela inadequação de um professor formado na cidade.

Hall também chamava a atenção para arquitetura da residência e da escola. Ao construir a casa dos docentes "não se cometeu o grave êrro psicológico de afrontar a comunidade local com uma casa luxuosa ou grandiosa, completamente fora do alcance dos membros da comunidade" (HALL, 1950, p.115). No tocante à escola, o pesquisador comparava a simplicidade das construções do programa aos prédios escolares encontrados nas cidades. A adoção de um padrão arquitetônico para as escolas fazia parte do plano do INEP e tinha funções bem específicas: deveriam ser prédios simples, de rápida edificação, arejados, higiênicos, sem grandes custos de construção e manutenção (INEP, 1948).

Os jardins, hortas e criação de animais presentes no currículo escolar permitiam, segundo Hall, educar as crianças, ensinando-as novas técnicas agrícolas. Estes conhecimentos eram transmitidos aos pais, permitindo sua difusão por toda a comunidade. Assim, a escola rural não representava apenas um local onde se aprendia a ler, escrever e contar, mas uma instituição capaz de educar toda a comunidade, incutindo-lhe novos hábitos de higiene e trabalho. Para o pesquisador estadunidense, a prova disso estava na rápida aceitação da escola pela população local que lhe copiava o modelo arquitetônico e as práticas agrícolas ensinadas (HALL, 1950).

Após apresentar seus temores e apontar as qualidades do programa que fizeram-no ter confiança no seu sucesso, Hall decidiu oferecer algumas sugestões para uma futura revisão e ampliação do projeto. Elas consistiam em: 1- prosseguimento do programa; 2- aceleração da 
formação dos professores rurais; 3- completa revisão dos programas das escolas primárias e normais rurais; 4- criação de novos tipos de instituições educativas.

Hall sugeria a continuidade do projeto até que a carência de escolas fosse completamente suprida, garantindo a todas as crianças em idade escolar o acesso ao ensino primário. O pesquisador estadunidense apontou, ainda, como principal falha do projeto a lentidão e pouco investimento para a preparação de pessoal. Segundo ele:

\begin{abstract}
A formação de professores rurais deve ser acelerada ao ponto máximo. Creio que maior percentagem dos fundos do INEP deveria doravante ser devotada a escolas para professores rurais e que seria conveniente instituir cursos intensivos para a formação de professores rurais, de modo a preparar professores em número suficiente para as escolas à proporção que se construírem. (1950, p.119).
\end{abstract}

Mesmo os cursos organizados anualmente pelo INEP pareceram a Hall insuficientes para formar no professor primário rural as habilidades e competências necessárias para este tipo de função. Por isso, ele sugeria a continuidade do curso Problemas de Educação Rural, levando-o a outras regiões e indicava dois critérios básicos para seleção dos bolsistas: todos deveriam provir de zonas rurais e passarem por um concurso, ao invés, de receberem indicação. O pesquisador propunha, ainda, uma completa revisão dos programas das escolas primárias e normais rurais:

Os novos programas devem ser elaborados nas áreas rurais, sobretudo nas escolas normais, com o auxílio das escolas primárias anexas ou vizinhas. Basicamente os programas devem surgir da comunidade local, no processo de experiência e crescimento de professores e autoridades locais, em colaboração com o público em geral. Os programas devem dar maior atenção à agricultura prática - jardinagem, criação de animais, etc. Também devem incluir o ensino de indústrias domésticas de produtos vendáveis a fim de aumentar a renda do agricultor durante os períodos de inatividade forçada. Devem incluir também uma parte bem desenvolvida e extremamente prática sôbre saúde e higiene - côntrole de malária, côntrole de fontes de água potável, construção e manutenção de instalações sanitárias etc. As disciplinas de classe, língua pátria, aritmética, história e geografia devem ceder lugar a um projeto de metodologia em que os alunos aprendam as matérias-instrumentos, como parte integrante de projetos mais amplos e gerais, relativos da vida cívica e da formação a assuntos da vida familiar, profissional. (HALL, 1950, p.123-124).

Hall considerava necessário limitar, quando não, dispensar dos currículos das escolas primárias e normais disciplinas como aritmética, língua estrangeira, história e geografia. Dando a estas instituições um caráter tecnicista, voltadas para promover uma melhoria nos métodos de produção e na vida do homem rural. Nas escolas normais rurais, os professores 
estudariam disciplinas práticas, por meio das quais aprenderiam técnicas modernas de produção e profilaxia, transmitindo-as nas escolas primárias rurais e, consequentemente, para toda a comunidade.

Já nos cursos de formação, os docentes entrariam em contato, de maneira breve e sucinta, com novos conhecimentos, relativos a questões nacionais e internacionais como o comunismo, a energia atômica, entre outros. Aprenderiam sobre a importância do seu trabalho para o desenvolvimento do país, a manutenção da Segurança Nacional e a construção da democracia. E ao retornar ao meio rural, nas regiões mais distantes do país, transformariam-se em "intérpretes" dos valores a serem disseminados entre a "massa ignorante" de trabalhadores rurais.

Para terminar, Hall apontava uma última sugestão a ser incorporada ao projeto: a criação de novos tipos de instituições de ensino, propondo que o INEP iniciasse uma série de pesquisas, buscando criar modelos de escolas diversificados e atualizados com as crescentes necessidades educacionais exigidas por um país em desenvolvimento. De sua parte, propunha o financiamento de dois tipos de instituição: escolas de pescadores, localizadas em regiões ribeirinhas e litorâneas. E, um segundo modelo, criados nos EUA, a chamada Escola Consolidada:

Trata-se de uma escola dotada de vários professores, localizada numa área rural e frequentada por alunos procedentes de uma grande área em torno da escola, mediante uma rede de ônibus de propriedade da escola. [...] Seu sucesso depende essencialmente de três fatores: uma rede razoável de estradas utilizáveis em todas as estações do ano, um ônibus que possa apanhar as crianças em vários pontos próximos da escola, e boa vontade de várias autoridades locais, para cooperar nesse esforço conjunto. Nos Estados Unidos tiveram essas escolas um sucesso enorme. (HALL, 1950, p.124-124).

Como pode ser visto, tratava-se um projeto bastante ambicioso, se considerarmos as condições brasileiras. Embora localizado na zona rural, esse modelo diferia, em muitos aspectos, com o planejado e efetivado pelo INEP: as escolas primárias rurais construídas tinham uma estrutura muito simples, regidas por apenas uma professora que ensinava alunos com diferentes níveis de instrução. A maioria das regiões onde as escolas eram instaladas possuíam estradas de terra e professoras e alunos não tinham acesso a carros ou ônibus, andavam a pé ou em carroças.

É provável que tal instituição pudesse trazer um maior nível de desenvolvimento para as regiões onde fossem construídas, visto que elas interligariam várias áreas rurais em torno da escola. Mas para tal, ela exigiria um grande investimento em melhorias da estrutura local, 
o que não fazia parte do plano do INEP, visto que a escola primária rural era criada para conter o êxodo, instruindo e habilitando a população rural a viver com maiores condições de saúde e trabalho. E, assim, transformar, aos poucos, o meio que habitavam. O programa não previa investimento na construção de estradas, fornecimento de transporte escolar, criação de bibliotecas, etc. Seria necessário, como salientou Hall, uma enorme contribuição dos governos locais, os mesmo que argumentavam não ter condições financeiras de construir e manter em funcionamento escolas de ensino primário.

\section{Considerações Finais}

No relatório Observações e Impressões sobre o Ensino Rural no Brasil (1950), Hall afirmava que a Universidade de Columbia havia dado autorização para que ele continuasse, pelos cinco anos seguintes, a estudar detidamente a educação brasileira. Todavia, não encontramos mais nenhuma fonte sobre sua estada no país, suas pesquisas ou uma possível colaboração com instituições educacionais brasileiras.

Chamamos a atenção para o fato de que após sua colaboração com o INEP, praticamente não encontramos, nos jornais brasileiros, informação sobre sua passagem pelo país. A última matéria encontrada, em 1952, apresentava-o numa lista de intelectuais que participariam de um intercâmbio, promovido pela Divisão Cultural do Itamaraty. Nenhuma pista, porém, foi encontrada sobre o tipo de atividade realizada neste intercâmbio.

Com relação ao programa, algumas fontes revelam o interesse de Murilo Braga em manter o intercâmbio com o pesquisador estadunidense e colocar em prática algumas de suas propostas. Um relatório, enviado por Hall a Braga, em 1951, apresentava uma avaliação sobre a possibilidade de instituir um curso de verão para professores rurais nos Estados Unidos. O pesquisador estadunidense considerava, naquele momento, inoportuna a execução de tal plano, devido à inviabilidade de financiamento por parte da Universidade de Columbia.

Não sabemos, ao certo, se Robert King Hall abandonou este projeto. O mais provável é que sim, visto que a partir de 1952 o INEP passou por algumas reformulações. Anísio Teixeira assumiu a instituição após a morte de Braga, num acidente de avião. Teixeira procurou dar ao INEP um caráter de instituto de pesquisa, deixando de lado iniciativas voltadas para execução de políticas públicas, como foi o caso do programa de educação rural.

Acreditamos, porém, que a ausência de Hall possa ser justificada pelo seu trabalho em outros países. Algumas fontes indicam que, em 1955, ele teria partido com sua família para a Arábia Saudita, onde atuou como diretor de treinamento de pessoal na Arabian American Oil 
Company (Aramco), uma importante companhia petrolífera saudita, hoje, a maior do mundo. Depois disso, a única informação que encontramos foi a de seu falecimento, 1981.

Sem dúvida, as viagens realizadas por este pesquisador e seu interesse pela educação brasileira, na década de 1940, foram resultado do contexto de aproximação entre Brasil e EUA. Sua trajetória intelectual, a facilidade com que transitava nos meios militares e educacionais estadunidenses revelava um acumulo de capital político e cultural que possibilitavam não só o financiamento para suas pesquisas, como sua inserção em países que eram, de alguma maneira, importantes para a manutenção da hegemonia estadunidense. Robert King Hall foi um intelectual que viveu a Guerra Fria, defendendo, claramente, os valores que o seu país, convenientemente, acreditava ter fundado: a democracia e liberdade individual. Suas propostas para o ensino rural brasileiro baseavam-se nestes dois princípios.

Assim como os ruralistas pedagógicos brasileiros, Hall apontava para a necessária organização de um modelo de ensino voltado a promover melhorias na vida do homem rural, aumentar produtividade e conter o êxodo rural. Contudo, enquanto intelectuais e políticos brasileiros empreendiam uma batalha contra as zonas urbanas, em defesa da zona rural, o pesquisador estadunidense via uma complementariedade entre essas duas áreas, ambas devendo ser valorizadas, tendo em vista o progresso e a unidade do país.

Os ruralistas brasileiros preocupavam-se em defender "os valores nacionais", abandonar a influência estrangeira e estabelecer um modelo de ensino próprio, baseado na realidade brasileira. Hall, por sua vez, sugeria buscar referências em países onde a educação rural promovia real progresso, e os EUA representavam uma destas nações.

O interesse do diretor do INEP em manter contato com Robert King Hall, ampliar o programa a partir das suas propostas e a tentativa de implementar uma escola consolidada em Sergipe, revelam o grau de influência que este pesquisar exerceu junto ao programa. Isto não impediu, contudo, que suas sugestões esbarrassem na falta de recursos e no hábito dos governos brasileiros em abandonar as políticas educacionais empreendidas, conforme ele mesmo havia notado. Para isso também concorreu as mudanças vivenciadas pela sociedade brasileira, com o aceleramento do processo de industrialização e a consequente urbanização advinda deste movimento.

Mas o que podemos dizer quanto ao programa de maneira geral? Em nossa pesquisa, nos deparamos com uma série de trabalhos que abordaram o ensino rural em estados como Rio Grande do Sul, Santa Catarina, São Paulo, Paraíba, Paraná, entre outros. Todos eles receberam financiamentos do INEP para a construção de escolas primárias rurais, e embora 
buscassem seguir as diretrizes do programa, em cada estado estas escolas apresentaram características próprias.

No Rio Grande do Sul e Minas Gerais, por exemplo, as escolas normais rurais conseguiram instituir um currículo voltado para a formação do professor rural. No primeiro, o rádio foi utilizado para promover a integração entre a escola normal rural e a comunidade, permitindo a aceitação dos professores pela população local (WERLE, 2011). O segundo, conseguiu, através da experiência na Fazenda do Rosário, criar um currículo completamente voltado para a formação do mestre rural, selecionando docentes da própria localidade (LOURENÇO FILHO, 1953; PINHO, 2009).

Mesmo com a concretização de algumas das metas traçadas pelo programa, as pesquisas realizadas chamam a atenção para os problemas enfrentados nas escolas primárias rurais: falta de docentes dispostos a fixarem residência em zonas afastadas da cidade, poucos recursos, desgastes das construções por falta de manutenção e evasão escolar. Evidenciando, assim, que a maior conquista do programa não foi instituir uma educação tipicamente rural, mas levar, pela primeira vez, o mínimo de instrução para regiões mais afastadas do país.

\section{REFERÊNCIAS}

HALL, Robert King Hall. Problemas de Educação Rural. Revista Brasileira de Estudos Pedagógicos. Rio de Janeiro, $\mathrm{n}^{\circ}$ 47, maio/agosto de 1950, 106p.

HALL, Robert King. A nova escola primária brasileira. Revista Brasileira de Estudos Pedagógicos. Rio de Janeiro, $n^{\circ}$ 64, p. 05-30, 1950.

HALL, Robert King. Observações e impressões sobre o ensino rural no Brasil. Revista Brasileira de Estudos Pedagógicos. Rio de Janeiro, v. XIV, nº 38, p. 110-125, Jan./Abr. 1950.

HOBSBAWN, Eric. A era dos extremos: o breve século XX (1914-1991). Tradução: Marcos Santarrita. São Paulo: Companhia das Letras, 1995.

LOCHERY, Neil. Brasil: os frutos da guerra. Tradução: Lourdes Sette. 1. ed. Rio de Janeiro: Intrínseca, 2015.

MACCANN, Frank D. Aliança Brasil-Estados Unidos (1937-1945). Tradução: Jayme Taddei e José Lívio Dantas. 1. ed. Rio de Janeiro: Biblioteca do Exército Editora, 1995.

MACCANN, Frank D. Brasil e Estados Unidos: dois séculos de relacionamento. In: SILVA, Francisco Carlos Teixeira da; MUNHOZ, Sidnei (Orgs.). Relações Brasil-Estados Unidos: século XX e XXI. 1. ed. Maringá: Eduem, 2011, p. 25-64. 
MENDONÇA, Sonia Regina de. Estado e educação rural no Brasil: balanço historiográfico e visão crítica. In: ENCONTRO DE HISTÓRIA DA ANPUH - RJ, 17., 2016, Rio de Janeiro/RJ. Anais do $\mathbf{1 7}^{\mathbf{0}}$ Encontro de História da ANPUH-RJ, Rio de Janeiro, 2016, p. 0108 .

MOURA, Gerson. Tio Sam chega ao Brasil: a penetração cultural americana. 7. ed. Rio de Janeiro: Brasiliense, 1991.

NASCIMENTO, Jorge Carvalho do. Memórias do Aprendizado. Maceió: Edições Catavento, 2004.

PRADO, Maria Lígia Coelho. Ser ou não ser um bom vizinho: América Latina e Estados Unidos durante a guerra. Revista USP, São Paulo (26), p. 52-61, junho/agosto de 1995.

SCHELBAUER, Analete Regina. Da roça para a escola: institucionalização e expansão das escolas primárias rurais no Paraná (1930-1960). Revista História da Educação, Porto Alegre, v. 18, no 43, p. 71-91, maio/ago. 2014.

VALIM, Alexandre Busko. Imagens vigiadas: cinema e Guerra Fria no Brasil, 1945-1954. Maringá: EDUEM, 2011.

Agradecimento: Esta pesquisa foi financiada com bolsa de mestrado fornecida pela CAPES.

\section{$\underline{\text { SOBRE OS AUTORES }}$}

\section{Adriana Mendonça Cunha}

Mestra em Educação pela Universidade Federal de Sergipe (UFS). Graduada em História (UFS). Integrante do Grupo de Estudos do Tempo Presente (GET/UFS/CNPq). E-mail: adriana@getempo.org

\section{ORCiD https://orcid.org/0000-0002-0377-8745}

\section{Dilton Cândido Santos Maynard}

Doutor em História pela Universidade Federal de Pernambuco (UFPE). Professor do Departamento de História da Universidade Federal de Sergipe (UFS), do Programa de PósGraduação em Educação (PPGED/UFS), Mestrado Profissional em Ensino de História (PROFHISTÓRIA) e do Programa de Pós-Graduação em História Comparada da Universidade Federal do Rio de Janeiro (UFRJ). Bolsista produtividade CNPq. Líder do Grupo de Estudos do Tempo Presente (GET/UFS/CNPq). E-mail: dilton@ getempo.org https://orcid.org/0000-0002-9780-0260 